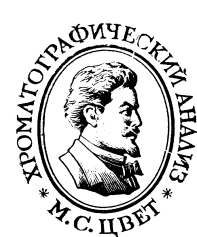

\title{
Научный отчет о проведении Восьмого Всероссийского Симпозиума «Кинетика и динамика обменных процессов» Фундаментальные проблемы SEPARATION SCIENCE
}

\author{
Боровикова С.А., Коломиец Л.Н., Шолохова А.Ю. \\ Федеральное государственное бюджетное учреждение науки \\ Институт физической химии и электрохимии им. А.Н. Фрумкина РАН, Москва
}

DOI: $10.17308 /$ sorpchrom.2020.20/2388

Восьмой Всероссийский симпозиум «Кинетика и динамика обменных процессов» был проведен в г. Москва с 18 ноября по 22 ноября 2019 года в Институте физической химии и электрохимии РАН. Симпозиум организован Институтом физической химии и электрохимии им. А.Н. Фрумкина Российской академии наук, Научным советом по физической химии РАН, а именно, Секцией совета «Физикохимия поверхности, кинетика и динамика обменных процессов». В работе Симпозиума приняли участие 149 человек, представляющих 34 организации, работающие в области хроматографии и аналитического приборостроения.

Научная программа симпозиума включала пленарные и секционные заседания по фундаментальным проблемам Separation Science: физико-химические основы Separation Science; фундаментальные задачи Separation Science; становление, развитие и перспективы Separation Science в России и в мире; приборные разработки для Separation Science; отечественные методические и программные разработки в области Separation Science; новейшие достижения в области сочетания хроматографических методов и массспектрометрии.

Интерес слушателей вызвал пленарный доклад проф., д.х.н. В.А. Даванкова (ИНЭОС РАН, Москва) «Неравновесные процессы в атмосфере: происхождение кислорода и органической материи». Из известных в астрономии планет только Земля имеет в атмосфере свободный кислород. В.А. Даванковым показано развитие представлений о возникновении кислорода на Земле. В 1988 г. им было высказано предположение, что главным источником кислорода является радиолиз паров воды в верхних слоях атмосферы с потерей водорода в космическое пространство и сохранением более тяжелого кислорода. Эта гипотеза за последние десятилетия приобрела массу подтверждений самых разных сторон с применением масс-спектрометрии, хроматографии, спектроскопии и других методов.

Новые аналитические задачи, возникающие в последние годы, стимулируют развитие хроматографических методов. Доклад чл.-корр. РАН О.А. Шпигуна (МГУ, Москва) «Тенденции развития жидкостной хроматографии» посвящен современным аспектам направления развития жидкостной хроматографии, позволяющим повышать селективность, эффективность, чувствительность. Для этого необходимы: колонки (новые функциональные группы на сорбентах) или системы колонок (двумерная ВЭЖХ) для повышения разделительной способности, экспрессные варианты (ультраскоростная ВЭЖХ), новые решения по снижению пределов детектирования. 
Д.х.н., проф. А.К. Буряк (ИФХЭ РАН, Москва) представил доклад «Функциональные материалы для противодействия техногенным вызовам», охватывающий возможности комплексного метода анализа, включающего масс-спектрометрию MALDI/LDI, термодесорбционную масс-спектрометрию, хромато-масс-спектрометрию и молекулярностатистические расчеты для анализа соединений, в том числе лабильных, на поверхности функциональных материалов. Представлены результаты практического использования данных методов: создан метод анализа поверхности для продления сроков эксплуатации изделий ракетной техники; предложен новый способ слива компонентов ракетного топлива из изделий после их длительного хранения; проведена оптимизация технологий обработки поверхностей; показаны возможности идентификации кластеров хлоридов металлов.

Доклад д.Х.н., проф. Р.Х. Хамизова (ГЕОХИ РАН, Москва) «Углеродные аэрогели - материалы нового поколения для сорбционных и электросорбционных процессов» был посвящен методам синтеза углеродных аэрогелей, всестороннему исследованию их физико-химических свойств, возможностям применения, главным образом, в качестве сорбционных материалов, а также в качестве пористых электродов для емкостной деионизации воды - перспективного метода, который в будущем может найти широкое применение.

В докладе д.Х.н., проф. И.Г. Зенкевича (Институт химии СПбГУ, Санкт-Петербург) «Эффекты дискриминации при дозировании проб в капиллярные колонки с делением потока» была отражена одна из важных особенностей использования капиллярных колонок в газовой хроматографии - дискриминация состава проб при их дозировании с делением потока газа-носителя. Подобные эффекты могут быть устранены только при дозировании проб в капиллярные колонки без сброса. Их можно минимизировать при увеличении деления потоков газа-носителя на сброс и в колонку. В остальных же случаях возможна их компенсация, если вместо абсолютных площадей пиков рассматривать отношения площадей пиков целевых аналитов и растворителей.

В докладе д.Х.н. Я.И. Яшина («Интерлаб», Москва) «ВЭЖХ природных полифенолов-антиоксидантов» приведены примеры определения полифенолов в некоторых пищевых продуктах и напитках, проанализированы основные обзоры по ВЭЖХ полифенолов. Показаны возможности методов высокоэффективной жидкостной хроматографии (ВЭЖХ) и УльтраВЭЖХ, двумерной ВЭЖХ, для разделения и выделения антиоксидантов.

Д.х.н., проф. В.А. Шапошник (ВГУ, Воронеж) представил доклад «Роль гидратации в ионообменных разделениях» об одном из важнейших явлений, определяющих свойства электролитов и физиологические функции живого мира, а также о ключевом понятии теории ионного обмена и хроматографического разделения веществ - гидратации. Показано, что открытие, сделанное В.А. Кистяковским 130 лет назад, даёт возможность современной интерпретации хроматографического разделения ионов.

В докладе д.х.н. В.Д. Красикова (ИВС РАН, Санкт-Петербург) «Биологически активные вещества из растительного сырья-особенности выделения, очистки, анализа транспортными методами» представлен краткий обзор развития современных методов исследования в области выделения и анализа природных БАВ на примере фитосахаридов, полифенолов и их композитов из продуктов быстро делящихся клеток картофеля Solanum tuberosum L.

Вечернее заседание первого дня Симпозиума открыл представитель японской компании «Frontier Laboratories» P.C. Герасимов с докладом «Пиролитическая хроматография как инструмент для обратного инжиниринга полимерных материалов». В своем выступлении он рассказал о пиролитических приставках к газовому хроматографу или хромато-масс-спектрометру, позволяющих проводить идентификацию полимеров и технологических примесей в них, а так же проводить испытания полимеров по отношению к УФ облучению. Важной деталью проведения данных работ является наличие внушительной базы данных, касающихся продуктов пиролиза полимеров и примесей в них, а также 
готовых методик определения природы исходных продуктов. Пиролизер в представленном варианте дает возможность без особых сложностей выполнять экспертные оценки, относящиеся как к происхождению изделий из полимеров, так и оценивать их свойства, качественный и количественный анализ добавок и токсичность материалов.

Д.х.н. А.М. Долгоносов (ГЕОХИ РАН, Москва) представил доклад «Модель межмолекулярного взаимодействия общего типа для описания удерживания полярных веществ в газо-жидкостной хроматографии» по результатам теоретического исследования. Было рассмотрено взаимодействие нейтральных молекул в изотропной среде с энергией, содержащей три независимые группы величин, описывающих полярные, неполярные силы и водородную связь. Найдена связь между индексами хроматографического удерживания и энергией взаимодействия аналитов с жидкой неподвижной фазой. Важно, что созданная авторами модель не требует эмпирических параметров и поэтому возможно ее использование для априорных расчетов характеристик хроматографического удерживания.

Д.х.н., проф. В.Н. Сидельников (ИК СО РАН, Новосибирск) представил интересный доклад «Технология создания упорядоченной структуры транспортных пор в хроматографической колонке». Главная проблема, которую рассмотрел автор: уширение хроматографических пиков, связанное с организацией транспортных пор в колонке и возможности его преодоления с помощью создания упорядоченных структур, например, поликапиллярных колонок. Сделан обзор того, какие в настоящее время существуют технологии для создания колонок с упорядоченными порами, так же рассмотрены возможности современной микромеханики для создания компактных многоканальных структур для изготовления капиллярных колонок с повышенной эффективностью.

Д.х.н., проф. Л.А. Онучак (Самарский университет, Самара) в своем докладе «Термодинамические и структурные аспекты супрамолекулярных взаимодействий «гостьхозяин» с циклодекстринами в объемных фазах и на поверхности сорбентов» остановилась на результатах расчетов и экспериментальных исследованиях взаимодействия летучих органических соединений с циклодекстрином и его производными в жидких фазах и на межфазной поверхности широкопористый адсорбент - газ, полученных методом обращенной газовой хроматографии. В докладе были представлены теоретическое обоснование расчета термодинамических характеристик комплексообразования в изотропных и самоорганизующихся анизотропных жидких фазах, экспериментальные данные по изучению комплексообразования с помощью различных хроматографических методов, а также другие важные аспекты исследуемой проблемы.

Большой интерес участников симпозиума вызвал доклад Д.Д. Матюшина (ИФХЭ РАН, Москва) «Предсказание индексов удерживания с помощью методов глубокого обучения». Работа интересна тем, что находится в русле современных тенденций развития методов предсказания свойств большого массива соединений на основании известной информации о взаимосвязи структуры и свойств для меньшего массива с использованием нейронных сетей. Для предсказания индексов удерживания авторы использовали в качестве независимых переменных, характеризующих молекулу, молекулярные дескрипторы и другие известные данные. Для всех типов неполярных неподвижных жидких фаз среднее относительное отклонение предсказанного индекса не превосходит $2.8 \%$. Это значение получено для аналитов различных химических классов и варьируется от класса к классу. Важно, что автор привел в докладе сравнение рассмотренного метода с молекулярно-статистическим подходом и объективно оценил не только преимущества, но и недостатки своего подхода и границы его применимости.

К.х.Н. А.Ю. Шолохова (ИФХЭ РАН, Москва) представила доклад «Нецелевой хромато-масс-спектрометрический анализ сложных многокомпонентных смесей с применением методов машинного обучения на примере продуктов, образующихся при пиролизе промышленных и бытовых отходов», который вполне можно назвать междисциплинарным исследованием, связанным с экологией, хромато-масс-спектрометрическим анализом 
и применением новых методов машинного обучения. На примере анализа продуктов пиролиза использованных шин и пластиков показаны возможности идентификации с использованием возможности методов машинного обучения и предсказания индексов удерживания в тех случаях, когда хромато-масс-спектрометрическая идентификация не дает уверенных результатов. Показано, что пиролизная жидкость для шин состоит из полиненасыщенных, ароматических полиароматических углеводородов, а также производных нафталина. В случае пластика пиролиз приводит к образованию алкенов и алканов, в то время как легкая его фракция содержит значительное количество алкилбензолов.

Д.х.н. И.А.Родин («Shimadzu», Москва) сделал доклад «Опыт эксплуатации хромато-масс-спектрометров Shimadzu на Химическом факультете МГУ им. М.В.Ломоносова», в котором автор с использованием и демонстрацией большого количества интересных примеров рассказал о возможностях хромато-масс-спектрометрии и особенностях этих спектрометров.

На утреннем заседании 19 ноября первый доклад был сделан М.Е. Чиварзиным (МГУ, Москва) «Оценка безопасности проб образцов чая, кофе и какао, основанная на селективном определении суммарного содержания галогенорганических соединений в этих матрицах», посвященный применению метода высокотемпературной окислительной конверсии органических соединений в потоке кислорода в сочетании с анализом абсорбата методом ионной хроматографии для оценки суммарного содержания галогенорганических соединений в образцах чая, кофе и какао. Результаты проведенных экспериментов позволили селективно по отношению к неорганическим солям определять суммарное содержание $\mathrm{F}, \mathrm{Cl}, \mathrm{Br}$ органических соединений в исследуемых образцах.

Д.х.н. Е.С. Бродский (ИПЭЭ РАН, Москва) в своём докладе обратил внимание на возможность использования распределения компонентов сложных смесей органических загрязнителей окружающей среды и изменения этого распределения во времени, под действием выветривания, бактериологического разложения, воздействия солнечного света для характеризации источников загрязнения. На примере смесей полихлорированных дибензодиоксинов, дибензофуранов и полихлорбифенилов показана возможность использования особенностей образования смесей загрязнителей определённого состава в зависимости от источника загрязнения для химического анализа и выявления такого источника.

Д.х.н. В.В. Милютин (ИФХЭ РАН, Москва) доложил о применении твёрдых экстрагентов (ТВЭКСов) на основе различных фосфорорганических соединений для извлечения редких и радиоактивных элементов из растворов сложного состава. Показаны результаты изучения сорбционных характеристик ряда ТВЭКСов.

Е.Ю. Олейниц (НИУ «БелГУ», Белгород) в своём докладе для определения констант комплексообразования фенольных кислот с циклодекстринами показала возможность использования обращено-фазовой хроматографии, выбрав условия, обеспечивающие минимизацию химической модификации обращённой фазы циклодекстринами. Это позволило оценить возможности использования других стационарных фаз для сорбатов, удерживаемых по механизму преимущественно поверхностной сорбции.

А.Г. Дорониным (НИУ «БелГУ», Белгород) для описания сорбции антоцианов на монтмориллоните (основном минерале бентонитовых глин) предложено новое уравнение для необратимой сорбции, свободное от погрешностей начального периода исследования. Экспериментально показано, что оно лучше описывает динамику сорбции антоцианов в предположении необратимой сорбции первого порядка с учётом степени заполнения поверхности глины по сравнению с уравнением Лагергрена.

А.С. Козырь (МГУ, Москва) продемонстрировала результаты исследования образцов конденсата выдыхаемого воздуха (KBB) человека методом газовой хроматомассспектрометрии. Были показаны результаты сравнения двух вариантов пробоподготовки: дериватизации лиофилизата КВВ и микросорбционного концентрирования аналитов из КВВ. Показано, что оба подхода дополняют друг друга при обнаружении следовых количеств неизвестных низкомолекулярных органических соединений в образцах КВВ. 
Е.В. Елисеева (Самарский университет, Самара) представила результаты изучения реакций превращения диарилтеллуроксидов и идентификации продуктов их трансформации методом хромато-масс-спектрометрии, наблюдаемые как при совместном присутствии нескольких диарилтеллуроксидов, так и в реакции альдольной конденсации. Были установлено, что в условиях электрораспылительной ионизации для диарилтеллуроксидов характерно образование димеров и ассоциатов с компонентами подвижной фазы.

Н.А. Редькиным (Самарский университет, Самара) показаны результаты исследования закономерностей построения многоуровневых систем идентификации материалов различной природы с использованием комплекса хроматографических, экстракционных методов в сочетании с масс-спектрометрией и ИК-Фурье спектрометрией. Предложена схема определения состава материалов, основанная на использовании ИК спектрометрии и экстракции для фракционирования компонентов материалов, определения их природы с последующим подбором хроматографической системы и комплекса методов идентификации.

Вечернее заседание второго дня конференции было открыто докладом д.х.н., проф. А.В. Булановой (Самарский университет, Самара) «Влияние природы наночастиц переходных металлов и способов их получения на активность катализаторов процессов гидрирования», который затрагивал не столько хроматографические процессы, сколько общие вопросы кинетики и динамики обменных процессов, определяющих активность катализаторов химических процессов.

Доклад А.А. Ядровой (Самарский университет, Самара) «Влияние ионных жидкостей на хроматографическое поведение некоторых бензимидазолов в условиях ВЭЖХ» посвящен рассмотрению особенностей поведения соединений выбранного класса (бензимидазолы) в условиях обращенно-фазовой ВЭЖХ в присутствии таких активно изучаемых в последнее время компонентов элюентов, как ионные жидкости.

Доклад к.ф.-м.н. Ю.А. Каламбета (ООО «Амперсенд», Москва) «Заострение пиков: старая технология на новый лад» затрагивал вопросы совершенствования алгоритмов повышения симметрии хроматографических пиков путем суммирования аналитических сигналов с их первыми производными.

В докладе Н.И. Горшкова (ИВС РАН, Санкт-Петербург) «Новые водорастворимые гибкоцепные сополимеры N-виниламина, содержащие дитиокарбаматный фрагмент: синтез и комплексный анализ методами ВЭЖХ и молекулярной гидродинамики и оптики» обсуждались вопросы синтеза и ВЭЖХ-анализа нового класса водорастворимых полимеров N-виниламина (не самого, а его более сложных производных), содержащих дитиокарбаматные фрагменты.

В выступлении к.Х.н. М.В. Шашкова (ИК СО РАН, Новосибирск) «Ионные жидкости как новый класс материалов для капиллярной газовой хроматографии» были рассмотрены возможности и особенности капиллярных колонок для газовой хроматографии с полярными ионными жидкостями в качестве неподвижных фаз. Из сказанного однозначно следует перспективность таких фаз, но их многообразие пока еще не позволяет выбрать какую-либо одну из них в качестве стандартной.

Сообщение Ю.С. Сотниковой (ИК СО РАН, Новосибирск) «Модификация in situ монолитных колонок для ВЭЖХ с органическими сорбентами» затрагивало современные подходы к модификации органических сорбентов монолитных колонок для ВЭЖХ, что существенно расширяет возможности этого типа разделительных систем в хроматографии.

И, наконец, заключительное выступление с интригующим названием «Нарушение массообмена. Кошмар хроматографиста» принадлежало П.В. Кудану («МС-аналитика», Москва).

Доклад д.Х.н., проф. В.А. Иванова (МГУ, Москва) открыл утреннее заседание 20 ноября «Перегретые растворы в ионообменных процессах разделения и очистки веществ», в котором были представлены теоретические оценки энтальпии сорбции одно- и 
двухзарядных катионов при разных температурах и результаты экспериментов на полиметакриловых и полиакриловых катионообменниках, проведенных при температурах выше $3730 К$, в которых были обнаружены очень сильные температурные эффекты, пригодные для использования в безреагентной технологии очистки и умягчения воды. Использование перегретой воды при повышенном давлении обусловлено сильным снижением диэлектрической проницаемости, что делает свойства воды похожими на свойства органических растворителей. Показано, что высокая селективность к двухзарядным катионам в условиях перегретой воды позволяет сорбировать их из сильно концентрированных растворов хлорида натрия.

Доклад «Выбор схемы и условий двухтемпературного ионообменного выделения тиоцианатов из растворов различного состава на основе изучения его равновесия и динамики» представила к.х.н. А.Н. Крачак (ГЕОХИ РАН, Москва), в котором проведено обоснование тиоцианатной технологии выщелачивания благородных металлов с позиций охраны окружающей среды и токсичности для человека. Показано, что возможно безреагентное температурное управление селективностью анионита для возврата тиоцианата в цикл для комплексообразования с выделяемыми металлами.

Е.А. Зайцева (ГЕОХИ РАН, Москва) в докладе «Классификация хроматографических фаз с помощью двухкоординатной карты селективности» рассказала о недостатках современных методов классификации хроматографических фаз, противопоставив им новую концепцию, основанную на фундаментальном описании энергии межмолекулярных взаимодействий, включающих неполярные, полярные силы и водородные связи. Новый метод позволил рассчитывать характеристики фаз по молекулярной структуре. Теоретический анализ данных по хроматографическому удерживанию различных веществ явился основой для способа определения параметров фаз по полярности и гидрофильности. Приведены примеры построения карты селективности неподвижных фаз для газовой хроматографии на базе развиваемого подхода.

Доклад «Влияние примесей железа, хрома и алюминия на разделение РЗЭ и ТПЭ методом вытеснительной комплексообразовательной хроматографии» представил д.Х.н. О.В. Харитонов (ИФХЭ РАН, Москва), в котором приведены исследовании влияния продуктов коррозии аппаратов для переработки отработавшего ядерного топлива на выделение РЗЭ и ТПЭ методом вытеснительной хроматографии. В качестве элюентов были предложены растворы НТА, ДТПА и лимонной кислоты. В ряде экспериментов по разделению целевых компонентов наблюдалось положительное влияние продуктов коррозии, которые выступали в качестве интеркаляторов, улучшая разделение РЗЭ. Показаны условия и результаты полной десорбции с ионообменных смол продуктов коррозии с помощью поочередного применения лимонной и азотной кислот.

В докладе к.X.н. Г.M. Шайдуллиной («Leco», Москва) «Увеличение пиковой емкости в двумерной хроматографии с использованием онлайн-сервиса LECO» рассмотрены возможности и проблемы сверхвысокого разрешения и идентификации пиков в многомерной газовой хроматографии. Показано, какие параметры требуется обеспечить в первой и во второй колонках, параметры записи данных и преимущества программного обеспечения LECO. Тем не менее, один из выводов работы касался необходимости создания программы-симулятора, позволяющей прогнозировать работу сложной системы, подбирать ее элементы и параметры, оптимизировать режим работы

Е.В. Рыбакова («Абакус», Москва) в своем докладе «Новое поколение ультраВЭЖХ систем Vanquish, Thermo Scientific, США» основное внимание уделила новшествам в ультра-ВЭЖХ системах нового поколения - конструкции узла ввода пробы под давлением и влиянию применения этого технического решения на качество хроматографического разделения при ультравысоком давлении и скорости. В общей сложности компанией Thermo в ультра-ВЭЖХ системах Vanquish реализовано около 30 патентованных технических решений. В заключении докладчик отметил, что ультра-ВЭЖХ система 
Vanquish с насосами, работающими на максимальном давлении 1500 бар, - в настоящее время является лидером рынка ультра-ВЭЖХ.

Д.Х.н. Г.В. Славинская (ВГТУ, Воронеж) в докладе «Влияние вида противоиона на влагосодержание сорбента» представила данные об изменение набухания ионитов при поглощении различных ионов. При растворении органических веществ количество воды уменьшается еще значительнее в гидратированном состоянии и вызывающие меньшее набухание. Этим способом размещения молекул, на взгляд автора, объясняется уменьшение содержание воды в ионитах при сорбции любых органических веществ: аминокислот, антибиотиков, фульвокислот и других органических соединений.

В докладе д.Х.н., проф. Е.В. Бутырской (ВГУ, Воронеж) «Механизм взаимодействии энантиомеров аланина с углеродными нанотрубками» показана возможность разделения L и D-аланина на новых хиральных сорбентах - углеродных нанотрубках (УНT). Показано, что L- и D-аланин сорбируются на поверхности УНТ не только в форме мономеров, но и кластеров. Моделирование систем УНТ+аминокислота методами квантовой химии также позволило сделать вывод, что D-изомер требует меньшей величины «посадочной площадки», чем L-изомер.

В докладе д.Х.Н., проф. О.Б. Рудакова (ВГАУ, Воронеж) «Низкотемпературные обменные процессы в водно-органических гетерогенных системах» рассмотрены процессы межфазного распределения некоторых органических соединений в водно-органических гетерогенных системах при отрицательных температурах. Показано, что эффективным методом концентрирования сравнительно гидрофильных соединений, является экстракционное вымораживание. Пока этот процесс не привлек к себе должного внимания, но он может найти прикладное применение в промышленной препаративной хроматографии биологически активных веществ (например, аминокислот).

К.х.н. В.Б. Хабаров (ИФХЭ, РАН) «Разделение гидратированных молекул этанола методом эксклюзионной ВЭЖХ» представил результаты анализа водных растворов этанола методом эксклюзионной ВЭЖХ на колонке с ПДВБ сорбентом и подтвердил, что этанол в зависимости от его концентрации с водой образует индивидуальные соединения.

А.Ю. Эльтеков (ИФХЭ, РАН) «Температурный эффект при взаимодействии ПАВ в хроматографической колонке с адсорбентом СБА-15» представлены данные по хроматографическому исследованию процесса взаимодействия молекул неионогенных ПАВ различной структуры и их ассоциатов в цилиндрических порах СБА-15 при 298 и 318 К.

После завершения пленарной части конференции начал работу мини-семинар компании «Абакус Аналитические системы ГмбХ», Германия. На семинаре сотрудник компании B.C. Харитонов выступил с докладом «Специальные CHNSO элементные анализаторы производства компании Elementar». В ходе доклада была озвучена техническая информация о приборах, их применении в науке, освящена методология элементного анализа. Участники конференции задали вопросы о пределах обнаружения органического углерода в ТОС анализаторе, о минимальной массе навески для анализа и ряд других вопросов.

Второе сообщение «Высокоэффективная ионная хроматография высокого давления в сочетании со спектральными детекторами» Рыбаковой Е.В. было посвящено последним тенденциям развития инструментов и метода ионной хроматографии. Было уделено внимание сочетаниям ионохроматографических систем Dionex с масс-селективными детекторами серии ISQ, а также сочетаниям ионной хроматографии с индуктивносвязанным плазменным масс-спектрометром, производства Thermo Scientific, США.

В докладе к.Х.н. Н.Л. Корягиной (НИИ гигиены, профпатологии и экологии человека, Ленинградская обл.), который открыл утреннее заседание 21 ноября, «Применение метода твердофазной микроэкстракции в сочетании с газовой хроматомассспектрометрией при определении метаболитов отравляющих веществ в биопробах» показаны различные направления использования метода ТФМЭ в сочетании с ГХ для определения продуктов гидролиза отравляющих веществ. Разработанные процедуры определе- 
ния метаболитов OB прошли апробацию на образцах биопроб, полученных в опытах in vivo на лабораторных животных.

И.Н. Фадейкина (Государственный университет «Дубна», Дубна) в докладе «Определение содержания косметических активов на поверхности кожи человека и изучение кинетики процесса переноса во внутренние слои кожи методами окситермографии и ИКспектроскопии» представила принципиально новый метод экспресс-окситермографии для количественного определения и идентификации косметических активов на поверхность кожи, который не требует пробоподготовки, дорогостоящих и опасных реагентов. Предложенный подход позволил получить количественные представления о концентрации витамина Е и гиалуроновой кислоты при нанесении на кожу и проанализировать изменение их содержания с течением времени

В докладе к.Х.н. Е.Н. Решетовой (Институт технической химии УрО РАН, Пермь) «Влияние вторичных равновесий при энантиоселективной адсорбции $\alpha$-арилпропионовых кислот на эремомицин-содержащей хиральной неподвижной фазе» предложена и обоснована модель адсорбции энантиомеров ионогенных соединений (ибупрофена и миндальной кислоты) на хиральной неподвижной фазе «Nautilus-E» с привитым антибиотиком эремомицином, учитывающая вторичные равновесия, оценены пределы ее применения и изучена роль ионообменных взаимодействий, вовлеченных в энантиоселективную адсорбцию. Продемонстрирована возможность описания хроматографического энантиоразделения в условиях одновременного и взаимозависимого действия двух разных типов вторичных равновесий - диссоциации аналита и адсорбции/десорбции компонента подвижной фазы - с помощью предложенной модели.

К.х.н. А.Н. Ставрианиди (МГУ, Москва) «Классификация ВЭЖХ-МС подходов, применяемых в анализе объектов природного происхождения» разработана система классификации ВЭЖХ-МС подходов, которая основана на направленности анализа на целевое и групповое определение и идентификацию, компонентов, построение образов исследуемого объекта («отпечатка пальцев»). Отдельный акцент сделан на способах обработки данных. Основным преимуществом предлагаемой системы классификации является возможность интегрировать в нее современные ответвления от указанных аналитических процедур, поскольку используемая фрактальная кривая предполагает бесконечное число усложнений предложенной системы.

В докладе к.Х.н. А.Ю. Канатьева (ИНХС, Москва) «Стабильность полимерных неподвижных фаз для газовой хроматографии» затронула актуальную задачу современной газовой хроматографии - поиск простой и надежной методики получения пористых полимерных слоев в капиллярных колонках. Одним из направлений решения этой задачи связано с использованием полимеров с внутренней пористостью. Хроматографическое исследование полимера PIM-1 позволило обнаружить у этого полимера специфические черты, проявляющиеся в процессе физического старения, и которые не были обнаружены методами мембранной химии.

Н.А. Бурнакова (МГУ, Москва) представила доклад «Разработка условий одновременного определения летучих жирных и фенилкарбоновых кислот в сыворотке крови методом газовой хромато-масс-спектрометрии», в котором проведен поиск условий для одновременного ГХ-МС определения микробных метаболитов в органическом экстракте, получаемом после жидкость-жидкостной экстракции (ЖЖЭ) из сыворотки крови.

В работе З.Б. Хесиной (ИФХЭ РАН, Москва) «Разработка методики извлечения, дериватизации и ГХ-МС определения метаболитов нескольких альфа-аминокислот в сыворотке крови и спинномозговой жидкости реанимационных пациентов» описана разработка методики извлечения, дериватизации и ГХ-МС определения соединений фенольной и индольной структуры в двух биологических матрицах (сыворотка крови и спинномозговая жидкость (СМЖ)), проведено сравнение различных подходов к пробоподготовке (жидкость-жидкостная экстракция (ЖЖЭ) и микросорбционное концентрирование в шприце, заполненном сорбентом C18 (MEPS)). 
Доклад «Определение пестицидов в водных объектах методом ВЭЖХ МС/MC с использованием дисперсионной жидкостно-жидкостной микроэкстракции ионными жидкостями» представил В.А. Деев (Институт химии СПбГУ, Санкт-Петербург), в котором изучено влияние природы ИЖ ([C6MIm][BF4], [C6MIm][NTf2], [C4MIm][PF6]) и диспергирующих растворителей (ацетонитрил, метанол, ацетон), времени экстракции, $\mathrm{pH}$ раствора пробы и концентрации соли $(\mathrm{NaCl})$ на степени извлечения пестицидов.

Заключительное вечернее заседание Симпозиума открыл д.Х.н. проф. С.М. Староверов (ЗАО «БиоХимМак СТ») докладом «Структура привитого слоя химически модифицированных кремнеземов: расчетные и экспериментальные данные». В докладе были представлены экспериментальные и литературные данные, объясняющие влияние размера пор и размера привитой молекулы на сорбционные и хроматографические характеристики сорбента.

А.Ю. Кирьянов (МГУ, Москва) сделал доклад «Сопоставление традиционных и непрерывных процессов выделения примесей субстанций лекарственных препаратов». В докладе представлены сравнительные данные по использованию новых непрерывных технологий, таких как MCSGP и N-Rich, обеспечивающих в ряде случаев увеличение производительности препаративного выделения субстанции в 10 раз.

Молодым ученым А.А. Дробь (МГУ, Москва) был сделан доклад на тему: «Кластерный анализ антоцианов как новый методический подход для анализа подлинности соковой и винодельческой продукции». Авторами доклада разработаны градиентные методы ВЭЖХ анализа, позволяющие разделить все 15 компонентов смесей антоцианов, что позволяет провести оценку содержания не только отдельных компонентов, но и рассчитать содержание родственных антоцианов, что является особенно актуальным при разработке новых методов оценки безопасности и подлинности продуктов питания. Важно отметить, что группу гликозидов на основе одного из гликонов авторы доклада назвали кластером.

С докладом по новым хиральным стационарным фазам на основе эремомицина выступил Н.А Сарвин (МГУ, Москва). Автором доклада изучен новый сорбент с привитыми хлорэремомицином, амидом эремомицина 2-адамантил амидом эремомицина и оритованцином при разделении $\alpha$ - и $\beta$-аминокислот и их производных. В докладе было также указано, что новые хиральные неподвижные фазы демонстрируют высокую селективность в отношении разделения энантиомеров $\alpha$-аминокислот на всех новых стационарных фазах на основе эремомицина и полученные закономерности позволяют локализировать возможные центры хирального распознавания.

Доклад на тему: «Оптимизация способов и устройств изготовления хроматодесорбционных систем для получения газовых смесей ацетона сделала М.А. Аникина (Самарский университет, Самара). В докладе было представлено, что анализ выдыхаемого воздуха на содержание летучих органических соединений, называемых биомаркерами физиологических процессов в организме, является одним из наиболее активно развивающихся направлений неинвазивной диагностики. В работе представлены результаты аналитического решения, связанные с разработкой и изготовлением устройств на основе хромато-десорбционных систем для концентрирования ацетона, относящегося к биомаркерам сахарного диабета.

Следующие доклады на темы: «Хромато-десорбционные системы для изготовления жидких сред с известным содержанием аналита» и «Хромато-десорбционные системы и их исследование в субкритических условиях» были представлены студентами А.С. Брыксиным и М.Ю. Лабаевым (Самарский университет, Самара). В докладах был предложен динамический хромато-десорбционный способ приготовления стандартных жидких водных, водно-органических сред, а также водных сред, находящихся в неидеальном состоянии, с использованием монолитных неподвижных фаз. Авторами доклада были изготовлены образцы полимерных монолитных неподвижных фаз, содержащих аналит, нанесенный на нанодисперсный адсорбент. Изучение работы таких систем проводилось с 
помощью экстракционной установки с использованием водного и водно-органического экстрагентов, а также воды, находящейся в субкритическом состоянии, в статическом и динамическом режимах при различных температурах и давлениях. Полученные экстракты были исследованы методами газовой и жидкостной хроматографии, выявлен ряд закономерностей, связанных с десорбцией и диффузией аналита, и предложено их объяснение.

C оригинальным устным заключительным докладом на тему: «Дифференциация прижизненно употребленного и новообразованного этанола в трупном материале» выступил д.Х.н. С.А. Савчук. В настоящее время участились случаи обнаружения этанола в крови детей, погибших в результате дорожно-транспортных происшествий. Часто эти случаи имеют широкий медийный резонанс, например, история с «пьяным» мальчиком Алексеем Шимко. Также экспертам приходится сталкиваться со случаями обнаружения очень высоких концентраций этанола у рабочих, получивших смертельные травмы на производстве, в крови пилотов, погибших в авиакатастрофах. Это требует разработки методов подтверждения факта прижизненного приема алкоголя лицом, погибшим при различных обстоятельствах, в которых употребление алкоголя запрещено и является отягчающим фактором. Поскольку кровь содержит глюкозу, способную образовывать этанол в результате микробной активности, предложено для получения более достоверных результатов отбирать мочу, в которой содержание сахаров мало, внутриглазную жидкость - объект наиболее защищённый от воздействия бактерий, а также весь доступный набор объектов: мышцу, мозг, печень, почку, спинномозговую жидкость. Все объекты консервируют добавление фторида натрия. Пригодность объекта к анализу устанавливают на основании результатов анализа сахаров, в крови не ниже 1 ммоль/л и по отсутствию маркеров брожения, деградации липидов и протеолиза: ацетальдегида, высших спиртов, ацетона, эфиров, летучих жирных кислот, метантиола и летучих сульфидов. Это исследование выполняют методом газовой хроматографии на колонке FFAP с массспектрометрическим детектированием и парофазным вводом пробы. Факт прижизненного употребления этанола доказывают по результатам определения минорного метаболита этанола - этилглюкуронида, который образуется под действием микросомальных ферментов печени, что предполагает наличие кровотока. Для определения ЭтГ использовали метод ВЭЖХ с тандемным масс-спектрометрическим детектированием. Разработанный подход был использован при проведении финальной экспертизы по «пьяному» мальчику и в ряде других экспертиз. 22 ноября участники Симпозиума приняли участие в организованной оргкомитетом обзорной экскурсии по Москве.

По итогам Симпозиума принято следующее решение:

1. $\mathrm{C}$ целью популяризации и ознакомления молодых ученых с историей открытия и развития отечественной хроматографии издать книгу по истории отечественной хроматографии к следующей юбилейной дате.

2. Участники Симпозиума выражают благодарность Организационному комитету за высокое качество проведения как научных, так и культурных мероприятий.

3. Выразить благодарность д.х.н., проф. В.Ф. Селеменеву и всей редакции журнала «Сорбционные и хроматографические процессы» за регулярную публикацию материалов Симпозиума в выпусках журнала.

4. Продолжить практику приглашения с докладами ученых, завершающих кандидатские и докторские диссертации.

Решение принято единогласно открытым голосованием на завершающем заседании Симпозиума 21 ноября 2019 года.

В феврале 2020 году лаборатория физико-химических основ хроматографии и хромато-масс-спектрометрии, которая ежегодно проводит Симпозиум «Кинетика и динамика обменных процессов», отмечает 70-летие со дня её основания. Первым заведующим лаборатории хроматографии был выдающийся учёный в области физической химии Константин Васильевич Чмутов (1902-1979). Достойным продолжателем традиций, заложенных в лаборатории К.В. Чмутовым, стал его любимый ученик д.Х.н. Олег Георгиевич Ла- 
рионов (1932-2013), который в 1979 г. возглавил лабораторию, а также стал Председателем Научного совета АН СССР по хроматографии, а ученым секретарем Научного совета стала к.х.н. Людмила Николаевна Коломиец. Вся научная и организаторская деятельность О.Г. Ларионова прошла в ИФХ АН СССР, где он прошел путь от лаборанта до заведующего отделом хроматографии. В 2004 г. д.Х.н. Алексей Константинович Буряк стал заведующим новой объединённой лаборатории, которая стала называться «лаборатория физико-химических основ хроматографии и хромато-масс-спектрометрии».

Сегодня в лаборатории физико-химических основ хроматографии и хромато-массспектрометрии ведутся работы по разработке методов нецелевого анализа. Для идентификации используют сочетание методов вычислительной химии, хемоинформатики и экспериментальных хромато-масс-спектрометрических методов. В последнее время были разработаны наиболее точные в мире методы предсказания газо-хроматографических индексов удерживания на основании структуры аналита. Один из методов основан на современных методах искусственного интеллекта (глубоких сверточных нейронных сетях) и позволяет предсказать индекс удерживания для газо-жидкостной хроматографии (полярные и неполярные жидкие неподвижные фазы). Другой подход основан на непосредственном моделировании адсорбции молекул на поверхности углеродного сорбента (газоадсорбционная хроматография) и является прямым продолжением работ А.В. Киселева. В последние годы разработан вариант молекулярно-статистического метода с учетом внутреннего вращения, позволяющий предсказывать удерживание на графитированной термической саже для конформационно нежестких молекул. Ведутся работы по дальнейшему совершенствованию методов предсказания удерживания в условиях газовой хроматографии. Разработан новый подход для применения индексов удерживания (предсказанных или содержащихся в базе данных) для идентификации с помощью масс-спектральных баз данных. Кроме того, ведутся работы по предсказанию фрагментации в различных методах масс-спектрометрии и анализа масс-спектров с помощью методов машинного обучения.

Основное внимание А.К. Буряка и его сотрудников уделено разработке физикохимических основ использования различных вариантов хромато-масс-спектрометрии при решении актуальных задач ракетно-космической отрасли. Разработаны методы исследования состава ракетных топлив, поверхностей конструкционных материалов и объектов окружающей среды, подвергающихся воздействию негативных последствий ракетнокосмической деятельности. Выполнены работы, имеющие большое значение для минимизации экологического ущерба от деятельности ракетно-космической отрасли.

Лаборатория сотрудничает с ведущими хроматографическими центрами нашей страны, представленные химическими факультетами: МГУ, Воронежа, Самары, СанктПетербурга, Новосибирска.

\title{
Scientific report on 8-th All-Russian Symposium "Kinetics and dynamics of ion-exchange processes» Fundamental problems of SEPARATION SCIENCE
}

\author{
Borovikova S.A., Kolomiets L.N., Sholokhova A.Yu. \\ Russian Academy of Sciences A.N. Frumkin Institute of Physical chemistry and Electrochemistry RAS \\ (IPCE RAS), Moscow
}

The symposium was held from 18 to 22 November 2019 at the Frumkin Institute of Physical Chemistry and Electrochemistry Russian Academy of Sciences (IPCE RAS). The scientific program of the symposium provided for the holding of plenary and sectional sessions on fundamental problems of the Separation Science: Physical and chemical foundations of the Separation Science; fundamental tasks of the Separation Science; formation, development and prospects of Separation Science in Russia and in the world; instrument designs for Separation Science; Russian methodological and program development in the Separation Science; the newest achievements in the field of combination of chromatographic methods and mass spectrometry. Also 
an expanded meeting of the Section "Physical Chemistry of the surface, Kinetics and Dynamics of Exchange processes" of the Scientific Council of the Russian Academy of Sciences on Physical Chemistry was held. The session was devoted to fundamental problems OF SEPARATION SCIENCE. The results of the Symposium decision was made: in order to popularize and familiarize young scientists with the history of the discovery and development of chromatography in Russia, to publish a book on the history of chromatography in Russia.

In addition, in 2020 the laboratory of physical and chemical foundations of chromatography and chromato-mass spectrometry, which holds this Symposium, celebrates the 70th anniversary of its foundation. Today, in the laboratory, which is headed by an scientist in the field of chromatography and chromato-mass spectrometry, corresponding Member of the Russian Academy of Sciences Aleksey Buryak, work is underway to develop methods for non-target analysis. For identification, a combination of methods of computational chemistry, chemoinformatics and experimental chromato-mass-spectrometric methods are used. The main focus this laboratory is given the development of the physical and chemical bases for the use of various variants of chromato-mass spectrometry in solving the actual problems of the rocket and space industry. 